This is a preprint of a chapter accepted for publication by Facet Publishing. This extract has been taken from the author's original manuscript and has not been edited. The definitive version of this piece may be found in Judy Dyki and Paul Glassman, editors, The Handbook of Art and Design Librarianship, second edition, 2017, Facet Publishing, which can be purchased from www.facetpublishing.co.uk. The author agrees not to update the preprint or replace it with the published version of the chapter.

\title{
Teaching with Threshold Concepts and the ACRL Framework in the Art and Design Context
}

Alexander Watkins, University of Colorado Boulder

\section{Abstract}

The ACRL Framework for Information Literacy posits six "big ideas" or frames, that an information literate individual understands. These frames are based on the educational theory of threshold concepts, and because of this theoretical basis the six frames are intentionally complex and wide ranging in scope. When the frames intersect with research practices within disciplines they take on different shadings and modulations, and are useful in different ways. When we apply the Framework from an art and design prospective, what might these ideas look like? This chapter explores the intersection of each of the six frames with art and design research.

\section{Introduction}

Teaching is at the core of the work of many librarians; as a field we are constantly trying to push our pedagogy forward in order to better teach information literacy. But how exactly do we define information literacy? And what skills and dispositions constitute information literacy? The way we articulate the definition of information literacy has a direct effect on how we teach it. The Information Literacy Competency Standards for Higher Education (the Standards), set forward a set of common skills and abilities an information literate students would possess. Now the ACRL Framework for Information Literacy (the Framework) posits six "big ideas" or frames, that an information literate individual understands. It represents the current culmination of a shifting pedagogical landscape in librarianship. The six frames are intentionally complex and wide ranging in scope. When the frames intersect with research practices within disciplines they take on different shadings and modulations, and are useful in different ways. When we apply the Framework from an art and design prospective, what might these ideas look like?

\section{The shifting landscape of information literacy pedagogy}

The adoption of the Framework and the rescinding of the Standards in 2016 was the result of a sea change in thinking about information literacy. Despite their usefulness, a simple update of the standards could not solve some of their intrinsic issues nor bring in them line with current teaching practices. The standards are essentially a linear progression of many discrete research 
skills and steps. By overloading on learning objectives and by giving everything equal priority, nothing was picked out as especially crucial (Hofer, Brunetti, \& Townsend, 2013, p. 110). Its proscribed order of steps suggested just one right way to carry out research and just one way to understand information literacy; its prescriptive approach models the workflows of privileged, high-achieving students whose work process most closely aligns with our own as academics and librarians (Elmborg, 2006, p. 194). The standards problematically do not address the social and political aspects of information literacy, and it has an essentially positivist construction of information, that is as absolutes separate from such contexts (Foasberg, 2015). The standards position students as mere finders and users of external and discrete units of information, rather than critical participants in their communities. This kind of document encourages the "banking" model of education, where learners are to be filled with predetermined information. The standards ended up stagnating library pedagogy by encouraging procedural tool-based training rather than building student's capacity to be independent critical users and creators of information.

Crucially the framework gives a new definition of information literacy, "Information literacy is the set of integrated abilities encompassing the reflective discovery of information, the understanding of how information is produced and valued, and the use of information in creating new knowledge and participating ethically in communities of learning." It contrasts sharply with the definition provided by the Standards, that information literate individuals "recognize when information is needed and have the ability to locate, evaluate, and use effectively the needed information." Several important concepts are embedded in the new definition, most importantly being that of learners as participants in communities and as creators of knowledge. The framework lists six concepts that together constitute key ideas of information literacy, and describes the knowledge practices carried out by information literate individuals (in other words, the visible actions that indicate comprehension of the ideas) and dispositions (in other words, the emotional and motivational states that allow students to apply the ideas) possessed by them. The six frames are:

- Authority Is Constructed and Contextual

- Information Creation as a Process

- Information Has Value

- Research as Inquiry

- Scholarship as Conversation

- Searching as Strategic Exploration

These complex concepts raise the bar for library instruction. They acknowledge that information and authority are social constructs that depend on context. It positions learners to take on more agency as potential participants in the information ecosystem, rather than as passive consumers of information. The framework does not list necessary skills or specific learning objectives, instead it was specifically designed so that libraries and librarians can use the Framework to create objectives that fit local and disciplinary needs. Thus, it will be up to art and design librarians to figure out how the framework's concepts relate to students in the visual arts, and what skills students will need to learn to support working in these concepts. By teaching students a contextualized version of the framework, librarians will not only support 
students' success in their chosen field, but can give them the tools to transfer their information literacy capacities to other aspects of their lives (Kuglitsch, 2015).

The Framework has not been without controversy or criticism. Some librarians have spoken out in defense of the standards and of standards based education, however as this author's stance on this matter are pretty clearly on view, I will leave it to others to make this argument. Much of the criticism unfolded during the public revisions that saw many changes to the frames as initially proposed. Additionally, the six frames certainly do not represent the totality of important information literacy concepts. Other frames have been proposed such as "information social justice" and "information apprenticeship in community" (Hinchliffe \& Saunders, 2015) and it will be interesting to see what other frames are proposed in the future. Another criticism from many librarians is that the frames do not go far enough or highlight strongly enough the social, political, and justice issues in information literacy. Instead of there being one social justice frame, these concepts are secondary parts of many of the other frames; which construction is superior is still a matter of debate. The frame information has value has been a focal point of criticism, as it has been argued that it adopts a neo-liberal framing that commodifies information and gives short shrift to important issues like information inequality, instead of making a strong statement about information access and the right to knowledge.

\section{Threshold concepts}

The Framework has its roots in the idea of Threshold concepts. These are complex and "troublesome" concepts that are essential to the epistemology of a discipline. They are troublesome because they are hard for learners to grasp and understand. On the other hand, experts have generally internalized the concept, such that it seems so obvious that it often is not stated explicitly. Often called bottlenecks or choke points, thresholds impede students' advancement in a discipline until they are mastered. Meyer and Land, education researchers who developed the threshold concept, liken them to portals that open new vistas of understanding, and as liminal spaces that once passed through cannot be repassed, and thus the learning of thresholds is often permanent (2003). They describe thresholds as typically having several of these five traits:

1. They are transformative, that is they change the way the learner views the world, or at least certain phenomena.

2. Irreversible, as stated it is hard to unlearn a new understanding. This also makes it difficult for experts to understand the position of a new learner who has not crossed this threshold, as it is difficult for them to imagine seeing the issue any other way.

3. Integrative, they involve the interrelatedness of concepts that might have seemed unconnected.

4. Bounded in a conceptual space. Threshold are usually specific to a discipline and incompatibility in them can suggest disciplinary boundaries.

5. Troublesome, this knowledge is often "alien" or "counter-intuitive," but also might be troublesome because it remains tacit and unspoken.

Let's take as an example, the frame "Scholarship as conversation," and examine how it aligns with this definition of a threshold concept. Once a learner understands this idea, it certainly 
changes the way they view academic works: no longer as a repository of only the purest facts, but instead as competing arguments and interpretations that create new knowledge and ideas. Once understood, it becomes hard to think of academic writing as anything other than discourse. It integrates several concepts students have trouble with, including why and how to engage with scholarly sources; why an original thesis is necessary; that they might disagree with the sources they cite; and it even elucidates the true role of citation in a scholarly essay, not just to "prove facts" but to engage in a dialog. While not bounded in a discipline, it is certainly bounded in the world of academia. Finally, this knowledge is troublesome, mostly because it is never explicitly taught or explained to most students, and indeed is somewhat counterintuitive. Students expect they are using scholarly sources because they are the most reliable, not because they are expected to engage in the scholarly conversation.

The use of the threshold concept theory in developing the Framework has been debated, with many questioning the value of threshold concepts (Townsend, Lu, Hofer, \& Brunetti, 2015; Wilkinson, 2014). While there is not room here to debate thresholds, it is worth mentioning that they are not universally accepted, and that some consider them essentializing, unverifiable, or even hedged to the point of incoherence. Nevertheless, however they are categorized it seems clear that the six concepts in the Framework stand on their own as core concepts and do not require an adherence to threshold theory to be useful organizing principles for information literacy instruction. This criticism led to the deemphasizing of threshold theory in the text of the Framework, consequently each of the concepts are simply called frames (Association of College and Research Libraries, 2015b). This solution seems perfectly reasonable to this author.

\section{Intersections of the frames with art and design research}

\subsection{Scholarship as conversation}

Scholarship is a discourse that involves evolving arguments, multiple perspectives, competing schools of thought, and differing interpretations. Novice learners tend to see scholarly sources as stand-alone and nearly infallible, and use them in essays by appealing to their authority. In order for learners to become more expert users of scholarly information they need to understand that "every scholar is working in a context, and is not the only voice of a discipline, a problem, or a question (Association of College and Research Libraries, 2015a)." It is also important to understand this happens over long spans of time as scholars negotiate meaning through books, articles, reviews, and presentations. Students who haven't grasped this threshold might take a single scholar's interpretation of an artwork as its one true meaning, a fact rather than argument and merely one perspective, a single data point in a large discourse. Instead researchers must seek out this conversation and discover its shape, path, and history. Having students explore footnotes is one way to teach this idea. They may think they are simply there to prove facts. Instead, they will discover that citations can serve a multitude of purposes, and that one of the main such purposes is to locate works in their disciplinary discourse, to refute and argue, to extend and expand. As they trace citations forward and back, it becomes clear that there is web of conversations expressed in footnotes. 
This concept can be extended to the visual arts: think of importance of locating an artwork in the ongoing art world conversation. Students writing an artist's statement or undergoing a critique must be able to explain their work's location in ongoing developments and currents in art. They need to be able to explain how their work relates and was influenced by other artists both past and present (Peterson, 2017). Garcia and Labatte discuss using this idea to make information literacy more relevant to artists, they do this by explaining that artists "must identify their place in art history and ideology (2015, p. 242)."

Another key aspect of this frame is students developing their own voice as scholars and artists. Their essays or artworks should be their entry into a conversation. Students may be intimidated to engage with scholars and artists on equal footing, but it is key that they recognize their work is part of a larger conversation and that it needs to critically engage with the theories, ideas, and arguments of others. Students who have grasped this concept participate in the conversation through an original argument expressed in an essay or an artwork.

\subsection{Research as inquiry}

Understanding that Research is a form of inquiry is a key frame to a student's success in their academic career. At its core this frame is the idea that research should focus on unsolved problems or questions and that the researcher should contribute new knowledge and original ideas. Understanding this frame means moving from summarizing and reporting to analyzing and argument. This frame is often an unspoken expectation in college level essays. Some students do come to college with this understanding, but this knowledge is unequally distributed depending on the preparation students received and the degree to which they have been acculturated to the norms of academia. Leaving this as an implicit requirement only increases the advantage of privileged students. Information literacy instruction can help level the playing field and increase the inclusivity of academia by making this expectation explicit.

Importantly, students are working towards developing original inquiries that fit within the context of a discipline-that a researcher works to understand the basics and gradually develops more complex research questions that create new knowledge. Art history students must learn how inquiry functions in the discipline. Students who have not yet grasped this concept might be researching a work of art, only to become frustrated that there is little to no information about it. They haven't yet understood that one of the main goals of research in the discipline is to explain unexplained art, to research context, genre, material, artist, style, period, or production (just a few among many possibilities) and make original connections to the specific work under study. This frame is closely tied to Scholarship as Conversation, as students will need to understand that new knowledge in art history often comes in the form of a reinterpretation where the scholar may argue for a different meaning in an already interpreted work or in the form of extension where scholars take a theory and extend it to new works.

In art and design disciplines this frame takes on an important new dimension. Our students are often practitioners who create things. Without a typical research paper, what does research as inquiry mean? To understand this frame in such a context, it's important to see design and art 
as the results of research that can indeed express new knowledge and meaning (Sullivan, 2004). It is logical that practice-based research is also a form of inquiry, one in which "human understanding arises from a process of inquiry that involves creative action and critical reflection (Sullivan, 2006)." Art can express, embody, and encode new meanings and discoveries, though the path of inquiry is less linear and its means of expression more ambiguous. If we can teach artists and designers that the concept of research as inquiry applies to their work, information literacy becomes essential to the artistic process and, I would argue enriches it.

\subsection{Authority is constructed and contextual}

This frame asks students to understand two important ideas that affect the concept of authority. The first is that authority is contextual: that depending on the question being asked the appropriate authority will differ. Whether a resource is the right fit depends on what the student's information needs are and in what context they will use this information. The art world contains many authorities from academics, to critics, artists, curators, gallerists, and more. Students will need to learn whose authority is appropriate in different contexts and for different questions. This is not to say that authority is meaningless and there are no good or bad sources, rather that an authority on one topic and in one situation is not necessarily an authority in another area or situation. For example, an auction house or gallery might be an authority on the value of a work of art and its provenance, but not on its meaning within the culture that created it.

The second ideas is that authority is a culturally constructed phenomenon that is based on a society's knowledge practices and ways of knowing. At issue for art historians is the exclusive nature of scholarly authority, grounded in western ways of knowing, that keeps out knowledge from other cultures (Smith, 1999). This is especially problematic in a discipline that frequently studies the cultural and religious objects of other societies. For example, indigenous knowledge of the arts, often passed down through oral tradition and apprenticeships, is not accorded the same authority as a scholar's textual research on that culture's art. Frequently, indigenous voices are considered primary sources to be analyzed as subjects. Alternatively, academic sources are secondary sources to be engaged with as an intellectual equal. The colonial nature of this relationship, where other societies have the raw art objects, and Western academia is where those objects are taken to be interpreted and given authoritative meaning, is deeply problematic. To combat this unconscionable arrangement, librarians can use this frame to teach that indigenous and academic authorities are the result of cultural ways of knowing, neither is inherently superior (Watkins, 2017). Rather it depends on context and questions the researcher has; in many cases indigenous sources will be more reliable.

\subsection{Information Creation as a Process}

This frame deals with the idea that how research is created and presented determines what it can tell the researcher. This frame does not suggest some strict hierarchy of sources. Students often have the mistaken impression that only scholarly sources are good and other sources are bad or biased, for example. Instead students should learn the strengths and weaknesses of 
source types and creation processes. The process of writing an article in the New York Times is different than the process that is used to create a scholarly article, but both are likely reputable and in-depth and each have very different strengths. Understanding these differences and the processes that create them allow students to select the type of source most likely to match their information need. In art and design, students will deal will many different information creation processes from those used to create art journals and fashion magazines to exhibition and auction catalogs.

Students should consider creation processes, authors, audience, and purpose when thinking about a source. For example, the journalistic approach found in magazines and newspapers will more effectively inform a researcher about the facts of an art event, while the analytical approach in a scholarly article may help them interpret the meaning of that event. A trade magazine's audience of practitioners in the field may mean it is more likely to discuss materials and process. The currency and reporting purpose of art magazines, newspapers, and blogs might make them the best source for contemporary artists or to situate their own work in the field. This frame is closely tied to Authority is Constructed and Contextual, because often particular types of sources are most commonly used by different groups to communicate. We can help students determine what each of these communities has to offer a researcher. For example, they may go to academics writing in scholarly books and journals for interpretations, critics writing in magazines and newspapers for aesthetic judgements, and curators writing in exhibition catalogs for relationships between objects and artists.

One interesting application of this principle is in images of works of art. Students need to think about how reproductions of art works are created and manipulated. Images taken by a museum will have quality control processes in place to ensure an accurate representation of the original, while many other sources of images may have been cropped, recolored or otherwise altered. When selecting an appropriate source for an image, students must consider their information need. In some cases, perhaps a quick google search will suffice. More likely students will need reliable color and cropping as well as good resolution and the ability to zoom in order to successfully conduct a visual or iconographical analysis. The researcher should also understand that they might need to see the art work in person to understand the true visual impact, materiality, or depth of a work.

\subsection{Searching as Strategic Exploration}

This frame went underwent several rounds of editing during the public feedback period of the framework, starting out as Searching is Strategic, changing into Searching as Exploration, and finally combining the two ideas (Association of College and Research Libraries, 2015b). This process greatly strengthened the frame, stressing the importance of understanding and strategically using search tools while also acknowledging the serendipity and exploration so crucial to art and design research. Students who have mastered this frame can select from a wide range of search strategies and match them with their information need and the affordances of the database they are searching, whether that database is Google or a specialized academic tool. They search iteratively, using their previous results and new knowledge to modify their searches as they go. 
In art and design, the librarian's role is often to facilitate serendipitous discovery and bring rigor to student's natural exploration through concept-mapping, browsing strategies, discovery tools, and search refinement techniques. Peterson discusses importance of exploration in allowing the research process to be infused with "curiosity, creativity, and a sense of wonder (2017)." Concept mapping in particular can be especially useful when working with art and design students, as their nebulous research interests cohere through the mapping process and connect to concrete topics like artists, styles, or techniques. Working collaboratively to concept map can help a student fill in missing concepts and crowdsource new artists who also work with the student's themes. Then the librarian can teach how to turn this wealth of terms into strategic searches. It is also important that students reflect on chance discoveries, to think about why, for example, a book was in a specific spot or one search brought up a result but a different search did not. Often by interrogating these discoveries we learn about the organizational principles that underlie these systems.

\subsection{Information has Value}

This frame focuses on the idea that information has value, both to powerful interests that wish to maintain control over information and profit from its value, and to regular people that leverage information for social change. That information has monetary value is often very clear to librarians in art and design. We provide our users with academic databases, professional resources like trend forecasts or market research reports, lavishly illustrated art books, access to image databases, all of which is expensive. The challenge is in getting students to recognize this value. They may not realize that during their time in school they are members of one of the most information privileged groups in the world. Most students have not considered that all this access essentially disappears after they graduate. It is important for students to understand the information inequality inherent in our current information ecosystem, and to question the morality and sustainability of our current closed access academic publishing system. Understanding this frame also means knowing that information does not just have monetary value, but also social value. Art and design disciplines exemplify how information can be leveraged to effect change for social good. Students can use their access to information to inform the creation of activist art, interventions, posters, or designs that solve problems and improve lives.

In art and design the value of information is especially relevant to the use and reuse of images. Images clearly have value as they are sold and licensed. Oftentimes this value is protected by ever lengthening copyright terms, but in other cases, such as images of public domain artwork, control is maintained by limited access to high-quality photography. The shrinking and privatization of our public domain heritage is an example of the influence of powerful interests and its direct effect on artists and designers.

But artists also have power. Fair use protects their right to appropriate and remix images, allowing them to satirize, parody, and critique, using existing images to explore new messages and themes. On the other hand, the images appropriated by artists have value to their original creator, and appropriation can feel more like theft and infringement than homage. Students 
often think of themselves as doing the appropriating, however they may feel quite different when it is their work which is appropriated by a more famous artist and sold for large amounts of money without attribution. Indeed, whose work is appropriated and who does the appropriation often mirrors the race, gender, and socio-economic hierarchies in our society. It is particularly important that art and design students grapple with the complexities of this frame in order for them to make informed and ethical use of images and information.

\section{Conclusion}

This chapter is a brief exploration of how the Framework can inform our information literacy teaching in art and design. It will be exciting to see how we continue to use these concepts to expand and elevate our disciplinary instruction. It is more important than ever that we work to create critical users and creators of information, who can participate actively in their communities. We should work to create artists, designers, and scholars who understand information systems and who can use their power to transform, advocate, and create.

\section{Works Cited}

Association of College and Research Libraries. (2015a). Framework for Information Literacy for Higher Education. Retrieved June 21, 2016, from http://www.ala.org/acrl/standards/ilframework

Association of College and Research Libraries. (2015b). History of the Framework for Information Literacy for Higher Education. Retrieved February 3, 2017, from http://acrl.ala.org/framework/?page_id=41

Elmborg, J. (2006). Critical Information Literacy: Implications for Instructional Practice. The Journal of Academic Librarianship, 32(2), 192-199. https://doi.org/10.1016/j.acalib.2005.12.004

Foasberg, N. M. (2015). From Standards to Frameworks for IL: How the ACRL Framework Addresses Critiques of the Standards. Portal: Libraries and the Academy, 15(4), 699-717.

Garcia, L., \& Labatte, J. (2015). Threshold Concepts as Metaphors for the Creative Process: Adapting the Framework for Information Literacy to Studio Art Classes. Art Documentation: Bulletin of the Art Libraries Society of North America, 34(2), 235-248.

Hinchliffe, L. J., \& Saunders, L. (2015). Framing New Frames: Expanding the Conceptual Space and Boundaries. Retrieved from https://www.ideals.illinois.edu/handle/2142/88407

Hofer, A. R., Brunetti, K., \& Townsend, L. (2013). A Thresholds Concepts Approach to the Standards Revision. Communications in Information Literacy, 7(2), 108-113.

Meyer, J., \& Land, R. (2003). Threshold concepts and troublesome knowledge: Linkages to ways of thinking and practising within the disciplines. University of Edinburgh. Retrieved from https://www.utwente.nl/ces/vop/archief_nieuwsbrief/afleveringen\%20vanaf\%20okt\%2 02005/nieuwsbrief_17/land_paper.pdf

Peterson, A. (2017). Mapping the Chaos: Building a Research Practice with Threshold Concepts in Studio Art. In S. Godbey, S. Wainscott, \& X. Goodman (Eds.), Disciplinary Applications of Information Literacy Threshold Concepts. Chicago, IL: Association of College and Research Libraries. 
Smith, L. T. (1999). Decolonizing methodologies: research and indigenous peoples. London: Zed Books.

Sullivan, G. (2004). Art Practice as Research: Inquiry in the Visual Arts. Thousand Oaks, CA: SAGE Publications.

Sullivan, G. (2006). Research Acts in Art Practice. Studies in Art Education, 48(1), 19-35. https://doi.org/10.2307/25475803

Townsend, L., Lu, S., Hofer, A. R., \& Brunetti, K. (2015, January 30). What's the Matter with Threshold Concepts? Retrieved from http://acrlog.org/2015/01/30/whats-the-matterwith-threshold-concepts/

Watkins, A. (2017). Teaching Inclusive Authorities: Indigenous Ways of Knowing and the Framework for Information Literacy in Native Art. In S. Godbey, S. Wainscott, \& X. Goodman (Eds.), Disciplinary Applications of Information Literacy Threshold Concepts. Chicago, IL: Association of College and Research Libraries.

Wilkinson, L. (2014, June 19). The problem with threshold concepts. Retrieved from https://senseandreference.wordpress.com/2014/06/19/the-problem-with-thresholdconcepts/ 